\title{
BAITUL MAL PADA MASA RASULULLAH SAW DAN KHULAFAUR AL-RASHIDIN
}

\author{
Moh. Ahyar Maarif*
}

\begin{abstract}
Abstrak:
Pembahasan utama pada makalah ini adalah keberadaan Baitul Mal sebagai pelopor utama dalam bidang keuangan yang sesuai dengan shariat Islam. Baitul Mal tidak hanya sebagai lembaga yang mengatur pemasukan uang negara, namun juga memiliki tugas yang begitu penting dalam pendistribusian uang hasil negara yang tersimpan di Baitul Mal, agar harta-harta tersebut dapat diterima oleh orang-orang yang berhak menerimanya. Dengan makalah ini, penulis menjelaskan secara singkat mengenai sumber pendapatan dan manajemen Baitul Mal yang dimulai sejak zaman Rasulullah SAW hingga pada masa pemerintahan Khulafau al-Rashidin. Keberadaan Baitul Mal ini bertujuan untuk mencapai salah satu tujuan dari negara, untuk menegakkan sistem kenegaraan yang berkenaan dengan pelaksanaan kewajiban muslim, seperti salat, zakat dan sebagainya.
\end{abstract}

Kata Kunci: Baitul Mal, Khulafau al-Rashidin, tujuan pendirian.

* Dosen Prodi Manajemen Pendidikan Islam, Fak. Tarbiyah, Institut Ilmu keislaman Zainul Hasan Genggong Kraksaan 


\section{PENDAHULUAN}

Islam dalam perjalanan sejarahnya banyak mengukir prestasi yang gemilang. Pada masa kejayaannya Islam menjadi mercusuar peradaban dunia, baik dalam aspek sosial, ekonomi, budaya, politik maupun ilmiah. Dan hebatnya, semua aspek tersebut mendunia karena berbalut shariat yang bersumber dari al-Qur'an, al-Sunnah, dan fatwa para 'alim ulama'. Bahkan banyak konsep pengelolaan negara ala kaum muslimin tersebut yang kemudian menjadi inspirasi banyak ilmuwan dan negarawan dari generasi-generasi sesudahnya.

Negeri-negeri Islam pada zaman pemerintahan Khulafau alRashidin, Dinasti Umayyah, Dinasti Abbasiyyah dan Dinasti Utsmani dikenal sebagai negeri yang makmur. Kesenjangan antara si kaya dan si miskin tidak terlihat mencolok, karena pemerataan ekonomi yang cukup baik. Dan salah satu pilar terpenting yang menopang pilar ekonomi tersebut, tanpa menafikan adanya kebocoran yang merupakan kesalahan manusiawi adalah system pengelolaan keuangannya yang dikelola berdasarkan shari'at yang bermuara di lembaga Baitul Mal.

Dalam hal ini, penulis ingin membahas tentang sejarah perkembangan baitul Mal pada masa Rasulullah SAW dan Khulafau al-Rashidin, yang mana baitul Mal memiliki peran sangat penting dalam mewujudkan peradaban manusia yang Islami khususnya dalam bidang ekonomi berdasarkan Al-Qur'an dan Al-Sunnah.

\section{PEMBAHASAN}

\section{Pengertian Baitul Mal}

Baitul Mal berasal dari dua kata dalam bahasa Arab, yaitu "bata - yabitu - baytan yang artinya rumah atau tempat tinggal, dan Mala - yamulu - mawlun/Malun yang artinya harta. ${ }^{1}$ Jadi secara etimologis, Baitul Mal berarti rumah untuk meletakkan, mengumpulkan atau menyimpan harta.

Adapun secara terminologis, Abdul Qadim Zallum dalam kitabnya Al-Amwaal Fi Daulah Al Khilafah menjelaskan, bahwa Baitul Mal

1 Firdaus Al-Hisyam, Kamus Lengkap 3 Bahasa Arab Indonesia Inggris, (Surabaya: Gitamedia Press, 2006), 104 dan 580. 
adalah suatu lembaga atau pihak (al-jihat) yang mempunyai tugas khusus menangani segala harta umat, baik berupa pendapatan maupun pengeluaran Negara. ${ }^{2}$ Baitul Mal juga dapat diartikan secara fisik sebagai tempat untuk menyimpan dan mengelola segala macam harta yang menjadi pendapatan negara.

\section{Sejarah Berdirinya Baitul Mal}

Istilah Baitul Mal muncul pertama kali pada tahun ke-2 hijriah pemerintahan Islam. Hal ini disebabkan karena adanya percekcokan antar sahabat dalam hal pembagian harta rampasan dari Perang Badar. ${ }^{3}$ Maka Allah turunkan ayat ke 41 dalam surat al-Anfal yang menjelaskan tentang seperlima dari perolehan harta rampasan adalah untuk Allah, rasul, kerabat rasul, anak-anak yatim, orang-orang miskin dan ibnu sabil.

Dengan turunnya ayat ini, Rasulullah SAW mulai merintis pembangunan Baitul Mal yang berfungsi sebagai suatu muassasah (lembaga), yang menangani pengeluaran dan pendapatan negara, serta berfungsi sebagai tempat penyimpanan harta kaum Muslimin. Sejatinya Baitul Mal sudah berdiri sejak masa Rasulullah SAW, namun belum terbentuk dalam suatu lembaga yang mempunyai tempat khusus dan diwan (administrasi) yang resmi. ${ }^{4}$

Pada masa Rasulullah SAW ini, Baitul Mal lebih mempunyai makna sebagai pihak yang menangani setiap harta benda kaum Muslimin, baik berupa pendapatan maupun pengeluaran. Dikarenakan belum mempunyai tempat khusus untuk menanmpung harta kaum Muslimin yang diperoleh dari ghanimah, maka Rasulullah SAW segera memerintahkan sahabatnya untuk segera membagikan harta tersebut kepada kaum Muslimin setelah peperangan, tanpa menunda-nundanya lagi.

Hanzhalah bin Shaifi adalah salah seorang sahabat yang ditunjuk oleh Rasulullah SAW, untuk menjadi katib (sekretaris) beliau dalam mencatat serta membagikan ghanimah tersebut setelah usainya

2 Abdul Qadim Zallum, Al-Amwal Fi Daulati al-Khilafah, (Beirut: Dar al-'Ilmi li al-Malayin, 1983), 15.

3 http://bataviase.co.id/node/155545

4 Willy Mardian, "Jejak Rekam Perjalanan Baitul Maal", dalam http:// telagaalkautsar.multiply.com/contacts (14 Agustus 2008). 
peperangan, Muaiqib bin Abi Fatimah Ad Dausiy sebagai penulis harta ghanimah, Az Zubair bin Al Awwam sebagai penulis harta zakat, Hudzaifah bin Al Yaman sebagai penulis taksiran panen hasil pertanian Hijaz, Abdullah bin Ruwahah sebagai penulis taksiran panen hasil pertanian Khaibar, Al Mughirah bin Syu'bah sebagai penulis hutang piutang dan mua'malat yang dilakukan negara, serta Abdullah bin Arqam sebagai penulis urusan masyarakat yang berkenaan dengan kepentingan kabilah-kabilah mereka dan kondisi sumber-sumber air mereka. $^{5}$

Jadi, pada umumnya Rasulullah SAW membagi-bagikan ghanimah tersebut pada hari tersebut. Oleh karena itu, saat itu belum ada banyak harta tersimpan yang mengharuskan adanya tempat atau arsip tertentu bagi pengelolaannya.

\section{Perkembangan Baitul Mal}

1. Masa Khalifah Abu Bakar As Siddiq (11-13 H/632-634 M) Abu Bakar dikenal sebagai khalifah yang sangat wara' (hati-hati) dalam masalah harta. Bahkan pada hari kedua setelah beliau dibaiat sebagai khalifah, beliau tetap berdagang dan tidak mau mengambil harta umat dari Baitul Mal untuk keperluan diri dan keluarganya. Pada masa kekhalifahannya di tahun pertama ini, Abu Bakar As Siddiq belum melakukan perubahan yamg drastis dalam pengelolaan Baitul Mal. Jika datang harta-harta dari wilayah-wilayah kekuasaan Khilafah Islamiyah, maka Abu Bakar membawanya ke Masjid Nabawi untuk membagikannya kepada orang-orang yang berhak menerimanya, dari harta-harta inilah pendapatan Baitul Mal didapat. Untuk urusan pembagian harta-harta ini, khalifah Abu Bakar mewakilkan kepada Abu Ubaidah bin Al Jarrah. Hal ini diketahui pada saat pembaiatan Abu Bakar menjadi khalifah, Abu Ubaidah berkata kepadanya, "Saya akan membantumu dalam urusan pengelolaan harta umat." ${ }^{6}$

5 M. Shiddiq Al Jawi, "Baitul Maal Tinjauan Historis dan Konsep Ideal" dalam http://msi-uii.net/baca.asp?katagori $=$ rubrik\&menu $=$ ekonomi\&baca $=$ artikel\& id=75, (04 Februari 2011).

6 Busthanul Arifin, dkk, Ensiklopedi Hukum Islam, (Jakarta: PT. Ichtiar Baru Van Hoeve, 2001), 186. 
Perkembangan administrasi pada zaman khalifah Abu Bakar mulai terlihat pada tahun kedua dari kekhalifahannya. Abu Bakar mulai merintis embrio baru Baitul Mal dalam arti yang lebih luas. Beliau membangun Baitul Mal di kota Sanah, sebuah kota yang berada di pinggiran kota Madinah dan tempat ini tidak dijaga oleh satu orangpun. Namun hal ini tidak berlangsung begitu lama, karena Abu Bakar pindah ke Madinah dan Baitul Mal yang berada di kota Sanah dipindahkan ke rumahnya. Abu Bakar menyiapkan tempat khusus di rumahnya yang berupa karung,dan hal ini berlangsung hingga akhir masa kekhalifahannya pada tahun $13 \mathrm{H}(634 \mathrm{M}) .^{7}$

2. Masa Khalifah Umar bin Khattab (13-23 H/ 634-644 M) Setelah wafatnya Abu Bakar, Umar bin Khattab menjadi khalifah pengganti Abu Bakar. Philip K. Hitti menggambarkan sosok Umar bin Khattab sebagai seorang yang sangat sederhana dalam kehidupannya, meskipun dia telah menjabat sebagai seorang Khalifah. Hitti menceritakan, bahwa Umar hanya memiliki satu helai baju dan satu jubah, yang keduanya penuh tambalan. ${ }^{8}$ Dari sedikit gambaran ini, dapat kita bayangkan sosok seorang khalifah yang begitu sederhana namun penuh tanggungjawab.

Pada masa kekhalifahan Umar inilah banyak terjadi penaklukanpenaklukan (futuhat) terhadap negara lain, seperti: Kisra (Persia) dan Romawi. Dengan adanya penaklukan-penaklukan ini, maka pundipundi harta kaum musliminpun semakin bertambah. Oleh karena itu, Umar berinisiatif untuk membangun sebuah rumah khusus untuk menyimpan harta, membentuk diwan-diwannya, mengangkat para penulis, menetapkan gaji-gaji pegawai dan membentuk angkatan perang.

Umar bin Khattab juga melakukan sedikit perubahan dalam mengatur administrasi pemasukan negara. Terkait dengan masalah pajak, Umar membagi warga negara menjadi dua bagian. Bagian pertama warga negara muslim dan bagian kedua warga negara non muslim yang damai (zimmi). Bagi warga negara muslim, mereka diwajibkan membayar zakat. Sedangkan bagi yang zimmi diwajibkan

7 Al-Hafidz Jalaluddin Al-Suyuthi, Tarikh Khulafa', (Beirut: Dar al-Fikr, t.th), 74.

8 Philip K. Hitti, History Of The Arabs, (Jakarta: PT. Serambi Ilmu Semesta, 2006), 219. 
membayar kharaj dan jizyah. Bagi yang muslim diperlakukan hukum Islam dan bagi dhimmi diperlakukan menurut adat dan kebiasaan yang berlaku. Untuk menjaga situasi agar tetap terkendali, Umar menetapkan wilayah Jazirah Arab untuk muslim dan wilayah luar Jazirah Arab untuk non muslim. ${ }^{9}$

Selama memerintah, Umar bin Khattab tetap memelihara dan mengoperasikan Baitul Mal secara hati-hati. Beliau menerima pemasukan dari sesuatu yang halal dan sesuai dengan aturan syariat, lalu menditribusikannya kepada yang berhak menerimanya. Dalam salah satu pidatonya Umar berkata: "Tidak dihalalkan bagiku dari harta milik Allah ini, melainkan dua potong pakaian panas dan sepotong pakaian musim dingin serta uang yang cukup untuk kehidupan sehari-hari sebagaiman orang Quraisy biasa, dan aku adalah seorang biasa seperti kebanyakan kaum Muslimin”. ${ }^{10}$

3. Masa Khalifah Utsman bin Affan (23-35 H/644-656 M)

Kondisi yang sama juga berlaku pada masa kekhalifahan Utsman bin Affan. Namun, karena pengaruh yang besar dari keluarganya, Utsman tidak terlalu memperhatikan tindakan bawahannya yang kerap mengeluarkan harta dari Baitul Mal tidak sesuai dengan ketentuan yang sebenarnya. Utsman meneruskan metode yang dibuat oleh Umar bin Khattab dalam mengatur administrasi Baitul Mal, namun sedikit perubahan yang dilakukannya adalah mengganti para pegawai yang dilantik oleh Umar dengan orang-orang dari keluarganya. Utsman juga memberikan khumus (seperlima) dari Baitul Mal kepada keluarganya dan Utsman menganggap bahwa hal ini wujud daripada silaturahmi yang diperintahkan Allah SWT. ${ }^{11}$ Sisi lain yang dapat diambil dari sosok Utsman bin Affan adalah sikapnya yang pemalu dan dermawan telah memperkenalkan tradisi mendistribusikan makanan ke masjid untuk para fakir miskin. ${ }^{12}$

4. Masa Khalifah Ali bin Abi Thalib

Pada masa kekhalifahan Ali bin Abi Thalib, kondisi Baitul Mal

9 Muhammad Ridwan, Manajemen Baitul Maal Wa Tamwil, (Yogyakarta: UII Press, 2004), 60.

${ }^{10}$ Busthanul Arifin, dkk, Ensiklopedi Hukum Islam, 186.

${ }^{11}$ Busthanul Arifin, dkk, Ensiklopedi Hukum Islam, 186.

${ }^{12}$ Busthanul Arifin, dkk, Ensiklopedi Hukum Islam, 186. 
ditempatkan kembali pada posisi yang sebelumnya yaitu berfungsi sebagai rumah tempat penyimpanan harta kaum muslimin dan pengalokasian dana serta dibelanjakan secara keseluruhannya untuk kemaslahatan kaum muslimin. Ali juga mendapatkan gaji dari Baitul Mal, sebagaimana yang diriwayatkan oleh Ibnu Kasir, bahwa Ali mendapatkan jatah pakaian yang hanya bisa menutupi tubuh sampai separo kakinya, dan sering bajunya itu penuh dengan tambalan. ${ }^{13}$

Sejarah mencatat akan kewaraan sang khalifah yang telah berislam pada usia 8 tahun ini. Ketika berkobar peperangan antara Ali bin Abi Thalib dan Mu'awiyah bin Abu Sufyan, orang-orang yang disekitar Ali menyarankan Ali agar mengambil dana dari Baitul Mal sebagai hadiah bagi orang-orang yang membantunya. Tujuannya untuk mempertahankan diri Ali sendiri dan kaum muslimin. Mendengar ucapan itu Ali sangat marah dan berkata, "Apakah kalian memerintahkan aku untuk mencari kemenangan dengan kelaliman? Demi Allah, aku tidak akan melakukannya selama matahari masih terbit dan selama bintang masih di langit." ${ }^{14}$

\section{Tujuan Dan Sumber Dana Baitul Mal}

a. Tujuan Pendirian Baitul Mal

Dibentuknya Baitul Mal dalam negara adalah karena Baitul Mal mempunyai peranan yang cukup besar sebagai sarana tercapainya tujuan negara serta pemerataan hak dan kesejahteraan kaum muslimin. Al-Maududi menyebutkan dua sasaran dan tujuan negara dalam Islam, yaitu: 1) Menegakkan keadilan dalam kehidupan manusia dan menghentikan kelaliman serta menghancurkan kesewenang-wenangan. 2) Menegakkan sistem berkenaan dengan melaksanakan kewajiban muslim, seperti salat, zakat, dan sebagainya. ${ }^{15}$

Islam sebagai agama yang memelihara hak-hak asasi manusia,

${ }^{13}$ Farid Ma'ruf, "Baitul Maal Dalam Tinjauan Sejarah”, dalam http://faridmaruf. wordpress.com/2007/01/12/baitul-mal-tinjauan-historis-dan-konsep-idealnya/, Maret 2009).

${ }^{14}$ Busthanul Arifin, dkk, Ensiklopedi Hukum Islam, 187.

${ }^{15}$ Busthanul, dkk, ... 187. 
menggariskan bahwa salah satu hak yang penting bagi setiap orang ialah bahwa orang yang tidak memiliki apa-apa harus dipenuhi keperluan hidupnya. Diantaranya fakir miskin dan orang yang meminta-minta, sebagaimana yang telah dijelaskan dalam al-Qur'an surat adz-Dzariat ayat 19 , yang berbunyi:

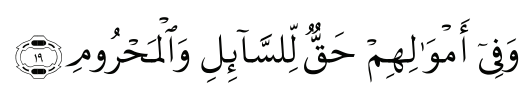

Artinya: Dan pada harta-harta mereka ada hak untuk orang miskin yang meminta dan orang miskin yang tidak mendapat bagian.

Untuk dapat memberikan hak kepada fakir miskin secara teratur diperlukan Baitul Mal yang dapat bekerja secara baik dalam menanggulangi ketidakmerataan kesejahteraan rakyat. Oleh sebab itu, tugas Baitul Mal adalah mengelola harta kaum muslimin yang tidak jelas pemilik dan penerimanya. Tugas itu menyangkut pemasukan harta, pemeliharaan apa yang terkumpul, dan pendistribusiannya kepada yang berhak menerimanya.

b. Sumber Dana Baitul Mal

Berbeda dengan kas negara zaman sekarang yang memiliki sumber dana dari berbagai sektor usaha. Menurut Imam al-Mawardi, Baitul Mal memiliki dua sumber yang pasti, yaitu: fai' dan zakat. ${ }^{16}$ Selain itu masih ada sumber-sumber lain, seperti: 1) Harta warisan orang yang tidak memiliki ahli waris, 2) Harta berupa benda-benda alam yang memiliki manfaat, seperti barang tambang, sumber air, sumber mineral, dan lain-lain, 3) Harta shuf'ah ${ }^{17}$, 4) Waqaf ${ }^{18}$, dan 5) Harta yang diwasiatkan lebih dari sepertiga. ${ }^{19}$

Fai' adalah harta yang diperoleh dari musuh non muslim bukan melalui peperangan, tetapi melalui perdamaian. Termasuk dalam fai' adalah jizyah dan kharaj. Jizyah adalah pajak perlindungan bagi orang kafir z \}immi, yaitu yang berlindung di bawah pemerintahan

${ }^{16}$ Penjelasan dapat dilihat di Imam al-Mawardi, Al-Ahkam Al-Sultaniyyah terj. Fadli Bahri (Jakarta: Darul Falah, 2007).210-248

${ }^{17}$ Harta Shuf'ah adalah harta priorotas yang diberikan serikat kepada salah satuanggotanya untuk menjualbelikan harta serikat, dengan syarat harta tersebut bukan harta yang bergerak, seperti tanah, tumbuhan, rumah,dll.

18 al-Qur'an, 3: 92.

${ }^{19}$ Busthanul Arifin, dkk, Ensiklopedi Hukum Islam, 188. 
Islam dan memiliki ikatan perjanjian damai dengan Islam. Adapun orang yang dikenakan jizyah adalah seorang laki-laki yang merdeka, baligh, berakal, hidup dan mampu bekerja. Pembayaran jizyah ini sebanyak 12 sampai 48 dirham setiap tahunnya, disesuaikan dengan pendapatan masing-masing. ${ }^{20}$

Kharaj adalah pajak tanah yang dikenakan kepada seluruh penduduk yang memiliki tanah, pada wilayah-wilayah yang sudah ditaklukkan oleh Islam sebesar 10\%. Pada zaman khalifah Umar bin Khattab, pajak ini disebut Kharaj al-Muqasamah yang mana pengurusannya diurus oleh kerajaan-kerajaan. Sedangkan pada masa khalifah Utsman disebut Kharaj bi al-iltiza>m, yang mana pengurusan pajaknya diurus oleh masing-masing pemilik tanah. Usyur adalah pajak perniagaan yang dikenakan kepada seluruh pedagang. Untuk pedagan yang kafir harbi dikenakan 10\%, bagi kafir $z$ immi 5\% dan bagi muslim 2,5\% apabila sudah mencapai nisab sebesar 200 dirham. Ghanimah adalah harta rampasan dan fai' yang didapat dari atau tanpa peperangan. ${ }^{21}$

Tidak semua sumber uang negara itu menjadi milik Baitul Mal. Kekayaan Baitul Mal ini sebagian besar ini berasal dari pajak tanah yang dimiliki oleh seluruh masyarakat dengan penggunaan yang sangat tergantung pada petunjuk imam atau para wakilnya. Yang masuk ke kas Baitul Mal adalah khumus (seperlima) dari ghanimah dan pajak hasil-hasil tambang serta harta temuan. Bagian inilah yang dapat dipergunakan untuk kepentingan masyarakat Islam seluruhnya. Sedangkan empat perlimanya dipergunakan untuk golongan-golongan yang telah ditentukan, seperti keluarga Nabi Muhammad SAW, anak-anak yatim, fakir miskin dan para musafir. Dengan demikian, bagian uang terakhir tersebut tidak berada di bawah pengawasan khalifah atau imam..$^{22}$

Selain itu, masih terdapat tiga sumber lagi harta yang masuk ke Baitul Mal, yaitu: 1) harta yang tidak ada pemiliknya, seperti

${ }^{20}$ Busthanul Arifin, dkk, Ensiklopedi Hukum Islam, 188.

${ }^{21}$ Yahaya dan Ahmas Jelani Halimi, Sejarah Islam, (Shah Alam: Fajar Bakti SDN. BHD, 1995), 173-174.

${ }^{22}$ Hasan Muarif Ambary, dkk, Ensiklopedi Islam, (Jakarta, PT. Ichtiar Baru Van Hoeve, 1999), 223. 
harta seorang budak yang lari dan harta yang ditemukan dari perampok yang tertangkap. 2) harta dari orang murtad. 3) tanah atau perkebunan yang pemiliknya telah meninggal dan tidak ada orang yang akan mewarisinya. ${ }^{23}$

\section{Manajemen Baitul Mal Dalam Sejarah}

Pada masa Rasulullah SAW, Baitul Mal belum memiliki DiwanDiwan tertentu, walaupun beliau telah mengangkat para penulis (katib) yang bertugas mencatat harta. Pejabat atau para penulis Baitul Mal dipilih apabila memenuhi syarat-syarat berikut, yaitu: a) Merdeka, b) Muslim, c) Berakhlak baik, d) Jujur, e) mampu bekerja. Seorang pejabat Baitul Mal juga harus mampu berijtihad, karena mereka yang akan menangani pajak yang meliputi kebebasan menentukan taksiran atau pengeluaran uang. Selain itu, agen-agen kecil yang kerjanya mengumpulkan atau menyampaikan pajak dapat saja seorang budak atau zimmi dari golongan yang seagama dengan mereka. ${ }^{24}$

Pada zaman kekhalifahan Umar bin Khattab inilah mulai dibentuk Diwan-Diwan Baitul Mal, baik berupa arsip ataupun tempat untuk menulis dan menyimpan arsip-arsip tersebut. Hal ini dikarenakan,pada masa kekhalifahannya Islam sedang gencar-gencarnya menaklukkan negara-negara di Jazirah Arab, yang secara otomatis menghasilkan banyak harta.

Umar bin Khattaab lalu bermusyawarah dengan kaum muslimin mengenai pembentukan Diwan-Diwan Baitul Mal tersebut. Diantaranya hadir Ali bin Abi Thalib, Utsman bin Affan, dan Al Warid bin Hisyam bin Al Mughirah. Pada saat itu, Ali ra. berkata kepada Umar, "Bagikanlah harta yang terkumpul kepadamu setiap tahun dan janganlah engkau tahan dari harta itu sedikitpun, Utsman berkata, Aku melihat harta yang banyak yang mendatangi manusia. Jika mereka tidak diatur sampai diketahui mana orang yang sudah mengambil bagiannya dan mana yang belum, maka aku khawatir hal ini akan mengacaukan keadaan". Al Warid bin Hisyam bin Al Mughirah berkata, "Ketika aku di Syam aku melihat raja-rajanya membuat Diwan-Diwan dan

\footnotetext{
${ }^{23}$ Hasan, dkk, Ensiklopedi Islam, 224.

${ }^{24}$ Hasan, dkk, Ensiklopedi Islam, 223.
} 
membangun angkatan perangnya”. Mendengar keterangan tersebut, maka khalifah Umar menyetujuinya. Kemudian ia memanggil beberapa orang keturunan Quraisy, yaitu Uqail bin Abi Thalib, Mukharamah bin Naufal, dan Jabir bin Muth'im. Umar lalu berkata kepada mereka, "Tulislah oleh kalian nama-nama semua rakyat berdasarkan kabilahkabilahnya”. Mereka melaksanakan perintah tersebut dengan memulai penulisan dari Bani Hasyim, kemudian Abu Bakar dan kaumnya, Umar dan kaumnya, serta diikuti dengan kabilah-kabilah lainnya. Kemudian mereka menyerahkannya kepada Umar dan ketika Umar melihat hal tersebut beliau berkata: Tidak, bukan seperti ini yang aku maksud, tapi mulailah dari kerabat Rasulullah SAW, yaitu yang paling dekat kepada beliau, maka tulislah kedudukannya itu sehingga kalian dapat menempatkan Umar sebagaimana Allah SWT telah menetapkannya. ${ }^{25}$

Adapun penggunaan uang Baitul Mal dibagi menjadi dua, yaitu: 1) untuk membiayai tugas-tugas negara, seperti gaji tentara, para pejabat negara, dan memelihara penjara. 2) untuk membuat jalan-jalan umum, persediaan air minum dan memperbaiki kerusakan tanah kharaj. ${ }^{26}$

Dalam pendistribusian harta yang tersimpan di Baitul Mal, Umar juga mendirikan: departemen pelayanan militer, departemen kehakiman dan eksekutif, departemen pelayanan dan pengembangan Islam, dan departemen jaminan sosial. Umar juga mendirikan diwan islam yang bertugas memberikan tunjangan-tunjangan angkatan perang dan pensiun. Tunjangan yang diberikan adalah sebagai berikut: 1) Aisyah dan Abbas bin Abdul Muthalib, masing-masing 12000 dirham. 2) . Para istri nabi selain Aisyah, masing-masing 10000 dirham. 3) Ali, Hasan, Husain dan para pejuang Badar, masing-masing 5000 dirham. 4) Para pejuang Uhud dan para migran abisinya, masing-masing 4000 dirham. 5) Kaum Muhajirin sebelum peristiwa Fathul Makkah, masing-masing 3000 dirham. 6) Putra para pejuang Badar, orang yang memeluk Islam ketika Fathul Makkah, anak-anak kaum Muhajirin dan Anshar, para pejuang perang Qadisiyah, Uballa, dan orang-orang yang menghadiri perjanjian Hudaibiyah, masing-masing 2000 dirham. 7) Orang-orang

${ }^{25}$ M. Shiddiq Al Jawi, "Baitul Maal Tinjauan Historis dan Konsep Ideal" dalam http://msi-uii.net/baca.asp? katagori $=$ rubrik \&menu $=$ ekonomi\&baca $=$ artikel $\&$ $\mathrm{id}=75$, (04 Februari 2011).

${ }^{26}$ Hasan, dkk, Ensiklopedi Islam, 224. 
Makkah yang bukan termasuk kaum Muhajirin, masing-masing 800 dirham. 8) Warga Madinah 25 dinar. 9) Kaum Muslimin di Yaman, Syria, Irak, masing-masing 200-300 dirham. 10) Anak-anak yang baru lahir yang tidak diakui, masing-masing 100 dirham. ${ }^{27}$

Disamping itu, harta Baitul Mal disalurkan pula untuk membenahi kepentingan umum yang dapat menunjang berjalannya pemerintahan secara baik, seperti membeli perlengkapan peralatan negara, membangun jalan, jembatan, irigasi dan sebagainya. ${ }^{28}$

\section{KESIMPULAN}

1. Baitul Mal sesungguhnya bukanlah lembaga privat atau swasta yang hanya menangani sebagian aspek kegiatan ekonomi umat, melainkan sebuah lembaga yang mengurusi segala pemasukan dan pengeluaran dari negara Islam (Khilafah).

2. Tujuan pendirian Baitul Mal adalah untuk membantu pemerintah dalam menegakkan keadilan, menghancurkan kesewenangwenangan dan menegakkan sistem yang berkenaan dengan pelaksanaan kewajiban. Selain itu, untuk mengorganisir pendapatan dan pengeluaran keuangan negara serta pendistribusiannya kepada orang-orang yang berhak menerimanya.

3. Gagasan konsep Baitul Mal yang ideal haruslah merujuk kepada ketentuan syariah, seperti dalam hal sumber pendapatannya. Sumber pendapatan Baitul Maal diantaranya adalah zakat, fai', jizyah, kharaj, usyur, ghanimah, harta warisan orang yang tidak memiliki ahli waris, barang tambang, harta shuf'ah, waqaf, harta yang ditinggal lari oleh pemiliknya, dan harta orang murtad.

4. Manajemen Baitul Mal pada masa Rasulullah Saw hanya berupa suatu lembaga yang menampung dan membagikan harta-harta kaum muslimin, dan belum memiliki tempat khusus. Baitul Mal dikelola secara intensif pada masa kekhalifahan Umar bin Khattab, dengan dibangunnya Diwan-Diwan yang digunakan untuk tempat menyimpan harta-harta kaum muslimin. Umar juga memberikan html.

${ }^{27}$ Mumbasithoh, "Ekonomi Islam", dalam http://mumbasitoh.4t.com/custom4_2. ${ }^{28}$ Busthanul Arifin, dkk, Ensiklopedi Hukum Islam, 189. 
gaji terhadap para pegawai Baitul Maal, pejabat negara dan pasukan perang Muslimin.

5. Dampak positif dari keberdaan Baitul Mal yang masih dapat dirasakan hingga saat ini adalah keberadaan Bank Shari>'ah sebagai lembaga penyeimbang keuangan masyarakat diantara bank-bank konvensional lainnya. Selain itu, Baitul Mal saat ini berkembang menjadi Baitul Mal wa al-Tamwil. 


\section{DAFTAR PUSTAKA}

Ambary, Hasan Muarif, dkk, Ensiklopedi Islam, Jakarta: PT Ichtiar Baru Van Hoeve, cet VI, 1999.

Dahlan, Abdul Aziz dkk, Ensiklopedi Hukum Islam, Jakarta: PT Ichtiar Baru Van Hoeve, cet V, 2001.

Firdaus Al-Hisyam, Kamus Lengkap 3 Bahasa Arab Indonesia Inggris, Surabaya: Gitamedia Press, 2006.

Hitti, Philip K., History of The Arabs, Terjemahan oleh R. Cecep Lukman Yasin dan Dedi Slamet Riyadi, Jakarta: Serambi, cet. II, 2010.

http://faridmaruf.wordpress.com/2007/01/12/baitul-mal-tinjauanhistoris-dan-konsep-idealnya/

http://msi-uii.net/baca.asp?katagori=rubrik\&menu=ekonomi\&baca $=$ artikel\&id $=75$

http://mumbasitoh.4t.com/custom4_2.html

http://telagaalkautsar.multiply.com/contacts

Mawardi (al), Imam, Al-Ahkam Al-Sult\}aniyyah terj. Fadli Bahri, Jakarta: Darul Falah, 2007.

Ridwan, Muhammad, Manajemen Baitul Maal Wa Tamwil (BMT), Yogyakarta: UII Press, 2004.

Suyuthi (al), Al-Hafidz Jalaluddin, Tarikh Khulafa', Beirut: Dar al-Fikr, t.th.

Yahaya, Sejarah Islam, Shah Alam: Fajar Bakti SDN BHD, 1995.

Zallum, Abdul Qadim, Al-Amwal Fi Daulati al-Khilafah, Beirut: Dar al'Ilmi li al-Malayin, 1983. 